\title{
Developing a strategy to improve irrigation efficiency in a temperate climate
}

\section{A case study in England}

\author{
Jerry Knox, Keith Weatherhead, Juan Rodríguez \\ Díaz and Melvyn Kay
}

\begin{abstract}
Irrigation is an essential component of agricultural production in England, but the water resources required are under intense pressure due to rising competition, demands for greater environmental protection and the longer-term threats from climate change. This paper describes the development of a water strategy for agriculture to assure its future sustainability by reducing water wastage and maximizing the benefit from the water used. Three themes have been defined - working together, making best use of available water and developing a knowledge base. The approaches described have international relevance to countries where agricultural irrigation is an important component of water abstraction.
\end{abstract}

Keywords: abstraction; agriculture; map; water resources; GIS

Dr Jerry W. Knox is a Principal Research Fellow and Dr Keith Weatherhead is a Senior Lecturer at the Centre for Water Science, Cranfield University, Cranfield, Bedfordshire MK43 0AL, UK. E-mail: j.knox@cranfield.ac.uk; k.weatherhead@cranfield.ac.uk.Dr Juan Rodríguez Díaz is a Senior Researcher at the University of Córdoba, Campus de Rabanales, 14071 Córdoba, Spain. E-mail: ma2rodij@uco.es. Melvyn Kay is with RTCS Ltd, Moorland House, 10 Hayway, Rushden, Northants NN10 6AG, UK. E-mail: kay@rtcs.co.uk.

Irrigated agriculture represents a small but significant component of land use in England in terms of production, value and rural employment (Leathes et al, 2008). In a dry year, about 150,000 ha are irrigated, supplying the UK food market with substantial quantities of high-quality vegetables (notably potatoes) and horticultural produce. Over half $(60 \%)$ of the total irrigated area and $57 \%$ of the total volume of water applied is in eastern England (Knox et al, 2000), one of the driest and most water-stressed regions of the UK. Irrigation is concentrated on highvalue crops, which do not receive European subsidy support, yet deliver substantial economic benefits. In East Anglia alone, irrigation supports 50,000 livelihoods, hence contributing over $£ 3$ billion annually to the region's economy. This excludes the additional benefits beyond the farm gate, where many businesses provide equipment and farm supplies, post-harvest processing and packaging, marketing, transport and distribution services related to irrigated production.

Despite its importance to the rural economy, the sustainability of irrigated production is under threat due to competition from other sectors (notably public supply), combined with new legislation to achieve greater environmental protection. There are also concerns regarding water reliability, as the majority of catchments in which irrigated production is concentrated are defined by the regulatory authority, the Environment Agency (EA), as being either over-abstracted or over-licensed during low-flow periods. These are effectively the summer months when irrigation need is at its peak. In 2006 , nearly a quarter (23\%) of the total volume licensed for irrigation abstraction in the Anglian region was from 


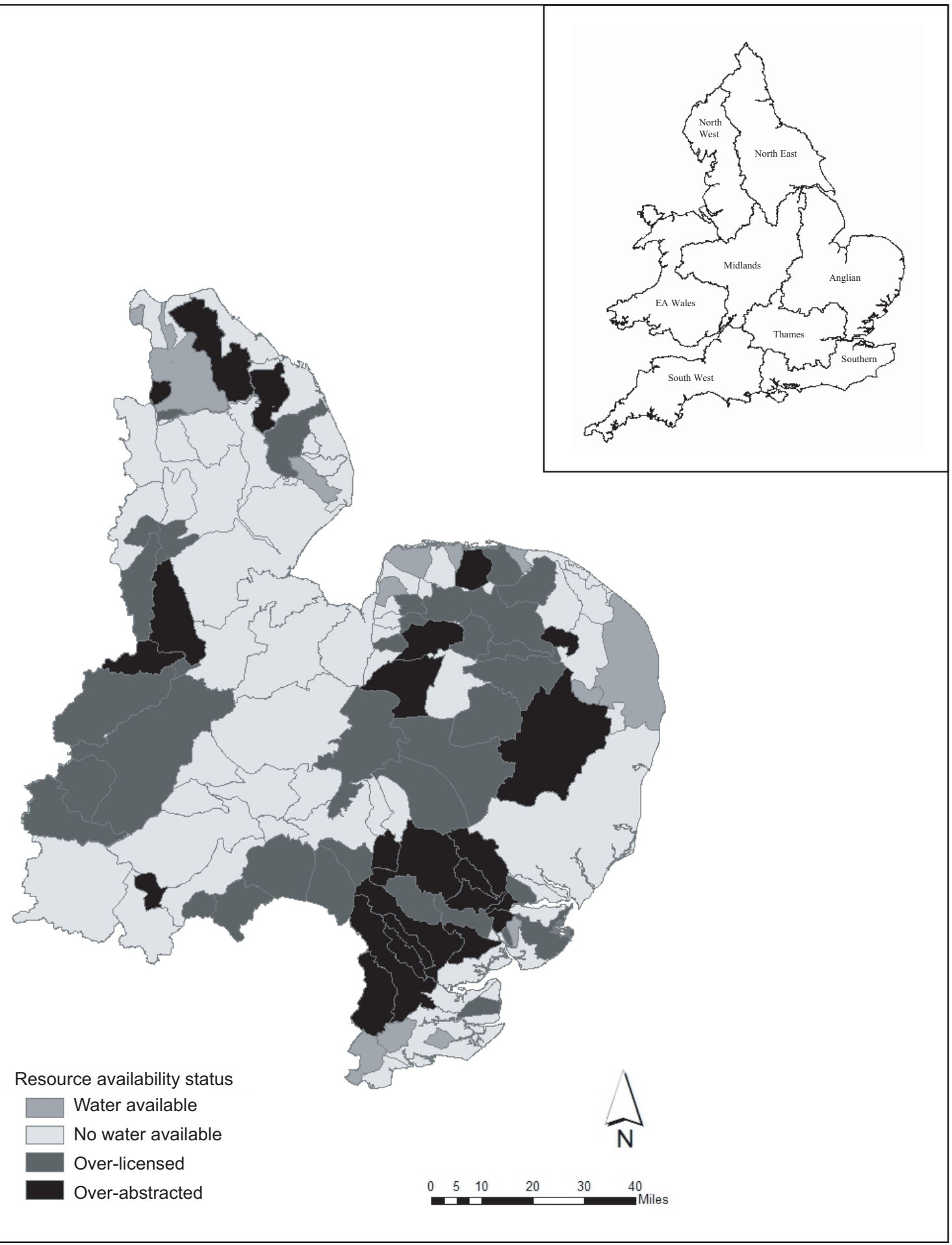

Figure 1. Environment Agency (EA) defined water resource availability in the Anglian region in 2008.

catchments defined as being 'over-abstracted', where existing abstractions were causing unacceptable damage to the environment at low flows. A further half (47\%) was from catchments defined as 'over-licensed', where unacceptable environmental damage would result if all existing licences were fully used. Only $9 \%$ was from 'water available' catchments, where additional summer low-flow water could be made available (Figure 1).
Whilst agriculture faces increasing uncertainty regarding water availability, the underlying demand for irrigation continues to grow, driven by supermarket demands for continuous supplies of premium-quality produce. Taking into account the annual variation in summer weather, which influences the agronomic need for irrigation, the total volume of water applied each year in England is growing at an underlying rate of $2.1 \%$ per 
annum; similarly, the total area irrigated is growing at a rate of $0.9 \%$ per annum (Weatherhead, 2006). These figures confirm that water is increasingly concentrated on high-value crops such as potatoes, horticulture (notably salads) and soft fruit (strawberries), and that these crops are receiving greater application depths. An additional concern is climate change, as irrigation internationally is considered by many to be the most sensitive of water uses and the sector that will be most impacted (Döll, 2002). In England, the impact of a changing climate, with hotter, drier summers and more frequent droughts, is likely to reduce water availability further (Henriques et al, 2008) and increase irrigation demand (Weatherhead and Knox, 1999). Indeed, recent forecasts by the Environment Agency predict increases in agricultural water demand in England and Wales for the 2050s of between 25\% and $180 \%$. The range reflects the high sensitivity of the socioeconomic scenarios used, depending on whether policies to promote sustainability or growth, a dematerialized society or material consumption, are adopted. These socalled 'axes of uncertainty' have been shown to impose a much greater degree of variability on future agricultural water demand than just climate change (EA, 2008).

Irrigation abstractors are also under public and regulatory pressure to demonstrate more efficient use of water. Supermarkets are exerting pressure through their grower protocols (for example, Tesco's Natures Choice) and water regulations require farmers to demonstrate efficiency as a condition of licence renewal. Clearly, without secure water supplies, many farms and agribusinesses would simply not survive; water scarcity would force a shift in land use away from intensive irrigated cropping to low-input cereal production, with significant adverse impacts for rural employment and economic productivity.

In 2007, following two dry years (2003 and 2006), the EA and East of England Development Agency (EEDA) commissioned the development of a water strategy for the agri-food sector. This was in response to the need for an evidence base on the environmental impacts of agricultural abstraction, coupled with concerns regarding rural employment. The objective was to build capacity within the agricultural sector to ensure it received a fair share of the available water resource and used it in a more sustainable and efficient way. Although the strategy was developed for eastern England, due to its high dependence on water for production, the strategy and its underlying principles are equally applicable to England as a whole, and indeed other countries where irrigation is an important component of the rural economy.

\section{Defining a strategic framework}

Although some farmers were starting to manage their water supplies better, initiatives to improve water efficiency and conservation across the industry were urgently needed. Some measures, such as adopting more scientific approaches to irrigation scheduling, could be undertaken by individuals, but others would need collective action due to the complex nature of water resources management. Following extensive consultation with key informants in the agri-food sector and with stakeholders in water and environmental management,
Table 1. Water strategy themes.

\begin{tabular}{|c|c|}
\hline Theme & Description \\
\hline $\begin{array}{l}\text { Working together to protect } \\
\text { water rights }\end{array}$ & $\begin{array}{l}\text { Improving dialogue between } \\
\text { individual abstractors, the agri- } \\
\text { food industry and the regulator }\end{array}$ \\
\hline $\begin{array}{l}\text { Making best use of available } \\
\text { water }\end{array}$ & $\begin{array}{l}\text { Improving the security of on-farm } \\
\text { water supplies and ensuring its } \\
\text { wise use }\end{array}$ \\
\hline $\begin{array}{l}\text { Developing a knowledge } \\
\text { base }\end{array}$ & $\begin{array}{l}\text { Improving water management } \\
\text { knowledge and skills training } \\
\text { within the agri-food industry }\end{array}$ \\
\hline
\end{tabular}

three themes were identified (Table 1). Development of the strategy involved combining data derived from deskbased research, collating farmer sentiment and opinion via stakeholder workshops, and using computer modelling and geographic information system (GIS) mapping. This paper describes the strategy, the rationale for each theme, the key actions required and plans for implementation.

\section{Working together to protect water rights (Theme 1)}

As in many countries, the 'voice' of water for agriculture in the UK is weak and fragmented and many farmers are disadvantaged when negotiating water rights with the regulator and influencing future water policy towards agricultural use. So developing farmers' institutional capacity by forming water abstractor groups (WAGs) to defend their existing water rights and build communication channels with the water regulator was considered essential to any future agricultural water strategy. WAGs exist worldwide, for example in Spain, Mexico, Peru, the Middle East, India, Nepal, Indonesia and the Philippines, many with a long and successful history. In most WAGs, farmers have faced water scarcity and decided to work together to minimize and share that scarcity in an equitable and sustainable manner. Despite the different cultures, their operating principles have been shown to be very similar (Trawick, 2003), and recent studies suggest that WAGs in England should be no different in this regard.

The concept of promoting WAGs was also supported by the EA, which viewed them as a mechanism for better communications with its licensed abstractors. For example, in eastern England there are 3,000 licensed irrigators - here the EA would prefer to deal with local groups of abstractors rather than 3,000 individuals during times of water stress (drought). Although six WAGs already operate in England - four in East Anglia, one in Lincoln and another in Northumberland, there has been a lack of urgency among farmers to initiate new groups, due to other more immediate commercial pressures, including regulation and uncertainties associated with EU Common Agricultural Policy (CAP) reform (Rickard et al, 2005). However, forming new WAGs is not straightforward, as both technical and social conditions must be right (Leathes et al, 2008). Dry years have highlighted the risks of water security to crop production, but 


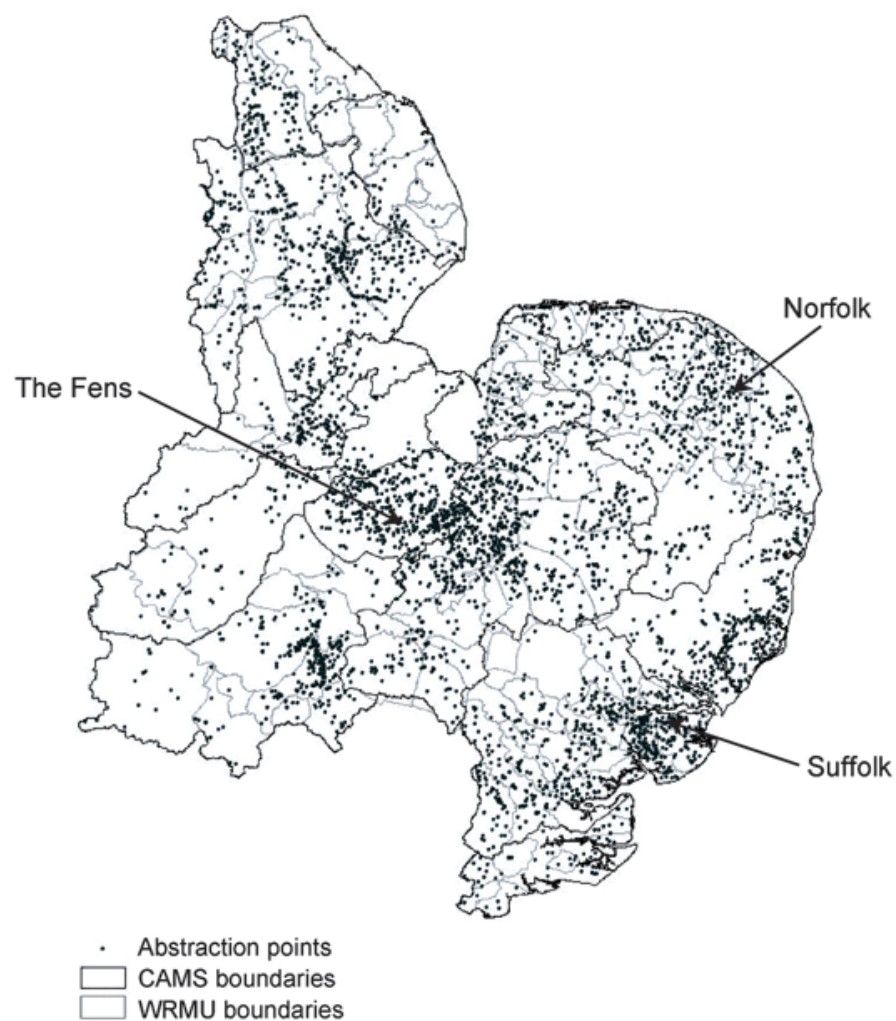

Figure 2. Location of spray irrigation abstraction licences in the Anglian region in 2008 .

Notes: CAMS = catchment abstraction management strategies; WRMU = water resources management units.

similarly, wet summers (2007 and 2008) have lessened the requirement to collaborate with neighbouring farmers. Another drought may well provide the catalyst for new groups, but waiting for that to happen is not necessarily the most rational way forward.

A fundamental question arose as to whether there was a way of assisting farmers to form new WAGs when there was no immediate crisis, and where to concentrate efforts. New groups are most likely to form where irrigation demand is high, where water resources are most constrained and where farmers are most willing to address the problem in a collective manner. A geographical assessment was needed taking into account spatial and temporal variations in climate, land-use and irrigation practices (Knox and Weatherhead, 1999). Using a geographical information system (GIS), the locations of abstraction points for agricultural irrigation relative to EA catchments were first mapped (Figure 2). This highlighted catchments in east Suffolk, north Norfolk and the Fens, where there is a high density of irrigation abstraction, corresponding to areas where favourable climate and fertile soils support intensive horticultural production. Then by correlating the volumes of water abstracted in a recent dry year (2003) against the spatial distribution of 'over-abstracted' areas (Figure 1), irrigation abstraction 'hot spots' were identified (Figure 3), where the formation of new WAGs was likely to be most successful. Such an approach would have relevance to many other countries where appropriate datasets are available.

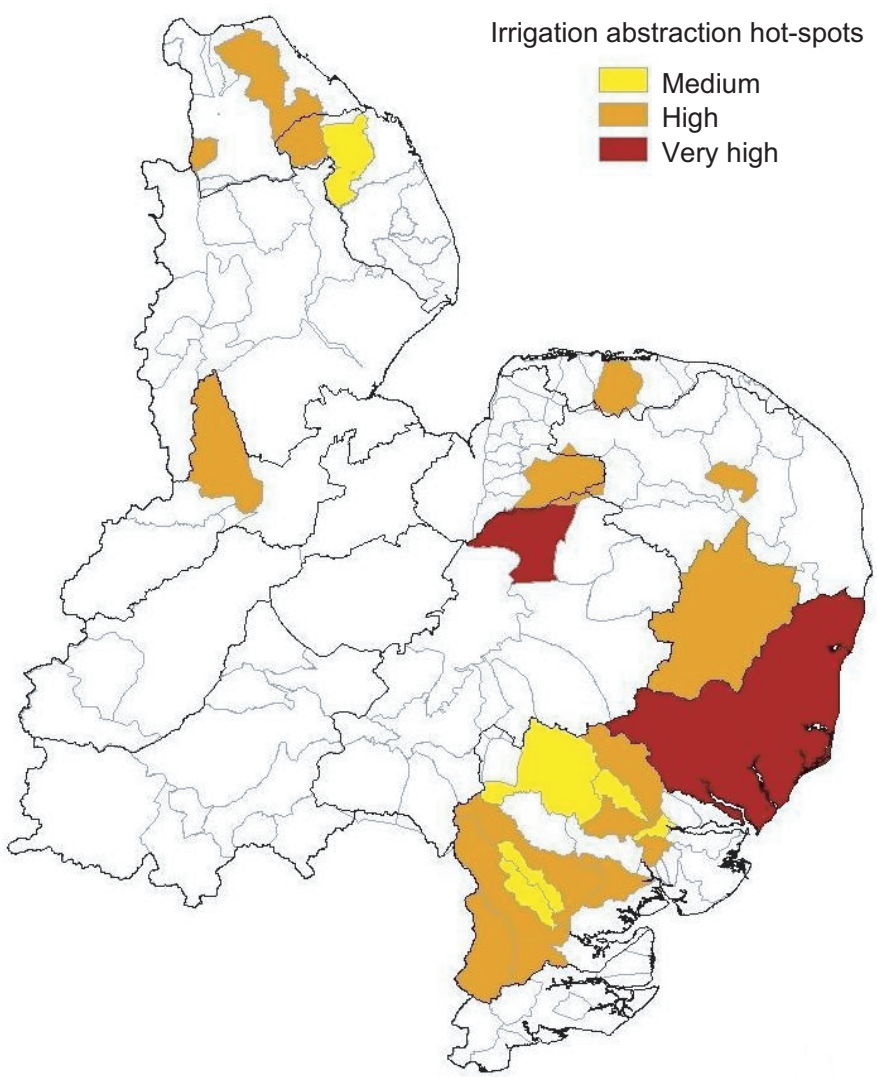

Figure 3. Identified spray irrigation abstraction 'hot spots' within critical catchments in the Anglian region in 2008.

In a number of 'hot spots' WAGs have already been formed, so the key actions in this theme were to support the formation of new WAGs in other 'hot spots' and also to help existing groups improve their water management skills. Strategic inputs would include advice and training on group management and administration as well as raising knowledge of local water resource matters. New groups would benefit from the experiences of the leaders of established groups, who would be encouraged to act as mentors. It is proposed that one new WAG is set up as a pilot, and once established, further groups should be set up using the experience gained. The more mature groups would be given support to develop into organizations with greater autonomy and local influence on water management.

\section{Making best use of available water (Theme 2)}

The second theme focuses on using the existing water more wisely. Most irrigators already aim to do this because saving water usually also saves money through reducing pumping, storage and labour costs. But more needs to be done to make better use of what is available, to obtain 'more crop per drop' (Luquet et al, 2005) or, even better, 'more value per drop'. Internationally, irrigation has a reputation for low efficiency (Molden, 2007), but irrigators in England use relatively little water by international standards, as the irrigation is supplemental, evapotranspiration rates are relatively low and there are 
no open canal networks or surface irrigation. However, there is always scope for using less. Making the maximum use of soil moisture and rainfall, knowing precisely where and when irrigation does have to be applied, and then applying it accurately and uniformly, are fundamental steps on the 'pathway to efficiency'.

\section{Using existing supplies better - benchmarking and new technologies}

International experience suggests that irrigation efficiency can be significantly improved by comparing how individual farms perform against industry best practice, through a process termed 'benchmarking' (Malano and Burton, 2001). This typically involves the development of Web-based systems, which enable farmers to input their irrigation data and to see how they compare against others irrigating under similar circumstances. Data are supplied anonymously to preserve commercial confidentiality. Key performance indicators include irrigation abstraction $\left(\mathrm{m}^{3}\right)$ and application $\left(\mathrm{m}^{3} / \mathrm{ha}\right)$, crop production ( $\mathrm{t} / \mathrm{ha}, £ / \mathrm{m}^{3}$ ), business processes and environmental impact. Benchmarking would provide UK irrigators with a means of comparing how they are performing relative to other growers, to help answer questions such as 'How well am I doing?' 'How much better could I do?' and 'How do I do it?' One of the recommendations of the strategy was to implement a benchmarking tool within a key crop sector (for example, potatoes), before extending into other sectors. Successful models developed in Spain (Rodríguez Díaz et al, 2008) and Australia (Malano and Davison, 2009) would inform the process.

Efficient irrigation also requires the adoption of best management practices using appropriate equipment with accurate water scheduling. As a relatively small player internationally, the UK irrigation industry needs to work with and build on the experiences of others. New technologies and better ways of using them are best found by studying developments in related sectors (for example, sensor technology and control systems in the glasshouse industry) and best practice in other countries, particularly those with similar crops, agroclimates and water resource problems. Those identified as most promising include:

- precision application systems - optimizing performance using equipment such as individually valved sprinklers, intelligent rain-guns and booms, and trickle irrigation (Knox and Weatherhead, 2005);

- improved scheduling using wireless sensors and/or infrared technology (Vellidis et al, 2008);

- reduced energy consumption by improving pumpsystem performance (Moreno et al, 2007); and

- understanding the impacts of poor efficiency on irrigation uniformity and crop production (Lacey, 2007).

A significant part of this theme involves the identification of potential advances, assessment of their appropriateness, and technology transfer. The work proposed combines networking with industry organizations and growers to define needs, study missions to identify useful advances elsewhere, detailed research studies on specific technologies and on-farm trials. The subsequent technology adaptation and technology transfer would include preparation of reports for grower audiences, grower networks and seminars, and on-farm demonstrations. Outreach and communication activities would then be coordinated by the UK Irrigation Association working alongside relevant crop sector levy boards responsible for sustaining UK agricultural and horticultural production. Similar initiatives are under way in Australia.

\section{Making more water available - trading, sharing and conjunctive use}

Even in a very dry year, less than a third of all water licensed for irrigation in England is actually abstracted. Of course, in some areas the water may not actually be available when needed, for example, due to low river flows or low aquifer levels, and additional abstraction would not be welcome from already over-abstracted catchments. Nevertheless, there is significant scope to increase the allocative efficiency of water for irrigation without causing environmental damage. In Australia, trading has helped move water from low- to high-value production, maximizing the value of water abstracted (Zaman et al, 2009).

Trading water permits (abstraction licences) is already possible in England, but can be administratively slow and cumbersome; renting the land with the water is widely practised to allow the long crop rotations required for crops such as carrots. Sharing can involve joint licences or less formal exchange arrangements. Most UK irrigation systems are independent, but linking systems enhances opportunities for conjunctive use of surface water, groundwater and reservoirs, greatly increasing reliability. This theme therefore involves identifying the real opportunities and issues involved in these initiatives - for example, how to match buyers to sellers in critically water-stressed catchments.

There are also opportunities for promoting shared reservoirs whereby neighbouring farmers share the investment and operating costs of a single larger reservoir, rather than many smaller ones. Here the strategy proposes research to identify the best ways to handle the legal, contractual and environmental issues of shared reservoirs and their environmental and resource benefits.

\section{Developing a knowledge base (Theme 3)}

Farmers need to stay informed and have access to the latest information at the right time if they are to remain competitive. The third theme involves developing a knowledge base to improve communication and dissemination of research. Experience in countries such as Spain has demonstrated the benefits of providing information on water management in formats that can be readily accessed by farmers (Rodríguez Díaz et al, 2005). Of course, UK irrigation is not on the scale of that in Spain or Australia, but a similar knowledge base that both captures existing information and provides a range of new media would significantly benefit the environmental sustainability and competitiveness of agribusinesses in England. It would also provide direct benefits to other stakeholders and the wider community, including those employed in the food and farming industries, as well as local schools and agricultural colleges. 


\section{Demonstration farms, Web-based information gateway and training}

Experience with organizations such as Linking Environment and Farming Marque (LEAF) has shown that on-farm commercially operated demonstrations can be very effective for highlighting and transferring new knowledge and experience between farmers.

Demonstration farms for water can help promote good land and water stewardship, identify alternative innovative approaches to adapting to water scarcity, and showcase new irrigation technologies and practices. They provide focal points for problem solving, networking and staff training. They can also inform and educate a wide range of other stakeholders about the role and importance of agriculture in the world of water. For example, educational field visits, guided tours and open days would provide local agricultural colleges, schools and the general public with opportunities to discover how water is an essential component in modern agri-food production, thereby helping to re-connect the public with the farming community.

The farming industry also needs better access to the latest information on water management. This includes guidelines on optimizing equipment, implementing best management practices, identifying opportunities for water saving, conducting water audits, and water policy and regulation. Most UK farmers use Internet services within their business, and so the Web and e-mail provide the ideal vehicle to deliver high-impact media such as factsheets, videos, programs, newsletters and research notes. An Internet-based 'one-stop shop' for information and advice on water management is proposed to contribute to skills development within the agri-food sector. This would also support the delivery of professional development training.

As part of the development of a knowledge base, a series of information booklets for farmers covering water issues has been published. These have been funded by the water regulatory authority and environmental protection and rural development agencies. The booklets cover subjects including water efficiency, storage reservoirs, water harvesting, WAGs, climate change, droughts and water scarcity, and irrigation scheduling. They have been distributed to registered irrigation abstractors across England and used in farmer training programmes. They have also been very popular with the international farming and scientific community (as evidenced by downloads from the UK Irrigation Association Website); this confirms that the approaches developed to cope with increasing irrigation water scarcity in a humid environment are equally relevant in more arid regions of the world.

Finally, professional development training is needed for both farmers and trainers. Farmers need to improve their technical knowledge in water management continually through workshops, short courses, technical meetings and conferences. Initiatives to date have been good, but limited in scope. In particular, they need promulgation across a much wider audience and to be targeted at catchments where water resources are stressed (Figure 3). Additional capacity is also needed to deliver this training. Most agricultural colleges do not have the required in-depth knowledge in agricultural and environmental water management; indeed, the land-based curricula in most agricultural colleges now provide only very basic coverage of such issues (Godwin et al, 2008). Training of trainers will thus be needed to build capacity and develop appropriate course curricula and training materials.

\section{Implementing the strategy}

In order to ensure that the strategy would be successfully implemented, a road map for implementation was developed to identify priorities and timescales. But the industry consultations emphasized quite strongly that it needed a 'champion' to promote and manage it. In England, the farming industry has many champions, but not one for water. Most organizations are commodity- or business-focused. For example, one levy board, the Agriculture and Horticulture Development Board (AHDB), represents the interests of growers in the cereals, potato, dairying, pig and horticultural sectors. Other organizations such as the National Farmers Union (NFU) represent agribusiness and land ownership interests. However, many of the stakeholders involved in the development of this water strategy recognized that all the efforts to reduce water wastage made by such organizations, though laudable, were disconnected. They are at best patchy and at worst lead to unnecessary duplication of effort, inefficient use of limited resources, and most importantly a fragmented and potentially weak lobby for the critical resource on which they all depend.

In this context, a water-saving centre or trust for agriculture was proposed to provide that focus, in much the same way that carbon and energy trusts have been formed in other business sectors. It would bring stakeholders together and champion the efficient use of water in agriculture, and would improve the potential for integrating the strategy actions. The centre would also act as a catalyst for supporting the development of WAGs, coordinate studies on key issues such as shared reservoirs and water trading, harmonize professional development training and manage the Web-based information gateway. Where additional resources or technical expertise were needed, the centre would commission specific studies in line with the water strategy. Although the establishment of such a centre was not a prerequisite for implementation, it was the preferred mechanism to ensure strategy uptake. Discussions between relevant regulators and stakeholders are under way to identify whether such a centre or trust can be established.

\section{An international perspective?}

The issues presented here facing farmers in England are not unique. They are similar to those in most other countries that rely on irrigated agriculture to some degree - in both developed and developing countries. Most farmers express concerns about the weakness of their negotiating position when seeking water and their need for a stronger 'political' and more cohesive voice to support investment in water for agriculture. They also express the need for information to support irrigation efficiency improvements and the desire to make best use 
of available and limited water resources. In most countries, they are the poor relation when it comes to sharing available water resources. These are themes now being discussed by the International Commission on Irrigation and Drainage (ICID), which represents some 80 different countries. These were also the main issues presented at the World Water Forum in Turkey in March 2009 in support of a fair share of water for agriculture. So lessons learned here could well have resonance in many other countries well beyond the UK.

\section{Acknowledgments}

This paper has arisen from research funded by the East of England Development Agency (EEDA), the European Social Fund and the Environment Agency (EA). The authors acknowledge the contributions of Lindsay Hargreaves, Tim Papworth, Tim Jolly and Robert Smith, the farmers who attended the various workshops and meetings, and members of the United Kingdom Irrigation Association (UKIA).

\section{References}

Döll, P. (2002), 'Impact of climate change and variability on irrigation requirements: a global perspective', Climatic Change, Vol 54, pp 269-293.

EA (2008), 'Demand for water in the 2050s - briefing note', Environment Agency, Bristol.

Godwin, R., Spoor, R., Finney, B., Hann, M., and Davies, B. (2008), The Current Status of Soil and Water Management in England, Royal Agricultural Society of England, Stoneleigh.

Henriques, C., Holman, I. P., Audsley, E., and Pearn, K. R. (2008), 'An interactive multi-scale integrated assessment of future regional water availability for agricultural irrigation in East Anglia and North West England', Climatic Change, Vol 90, pp 89-111.

Knox, J. W., Morris, J., Weatherhead, E. K., and Turner, A. P. (2000), 'Mapping the financial benefits of spray irrigation and potential financial impact of restrictions on abstraction: a case study in Anglian Region', Journal of Environmental Management, Vol 58, pp 45-59.

Knox, J. W., and Weatherhead, E. K. (1999), 'The application of GIS to irrigation water resource management in England and Wales', Geographical Journal, Vol 165, No 1, pp 90-98.

Knox, J. W., and Weatherhead, E. K. (2005), 'The growth of trickle irrigation in England and Wales: data, regulation and water resource impacts', Irrigation and Drainage, Vol 54, pp $1-9$

Lacey, T. (2007), 'Promoting the efficient use of water, and reducing environmental impacts, in horticultural field vegetable irrigation', unpublished $\mathrm{PhD}$ thesis, Cranfield University, Cranfield.

Leathes, W., Knox, J. W., Kay, M. G., Trawick, P., and Rodríguez Díaz, J. A. (2008), 'Developing UK farmers' institutional capacity to defend their water rights and effectively manage limited water resources', Irrigation and Drainage, Vol 57, pp 322 331.

Luquet, D., Vidal, A., Smith, M., and Dauzat, J. (2005), 'More crop per drop: how to make it acceptable for farmers?' Agricultural Water Management, Vol 76, pp 108-119.

Malano, H., and Burton, M. (2001), Guidelines for Benchmarking Performance in the Irrigation and Drainage Sector, International Programme for Technology and Research in Irrigation and Drainage, Rome.

Malano, H., and Davison, B. (2009), 'A framework for assessing the trade-offs between economic and environmental uses of water in a river basin', Irrigation and Drainage, Vol 58, pp 133147.

Molden, D. (2007), Water for Food, Water for Life: A Comprehensive Assessment of Water Management in Agriculture, Earthscan, London.

Moreno, M. A., Carrión, P. A., Planells, P., Ortega, J. F., and Tarjuelo, J. M. (2007), 'Measurement and improvement of the energy efficiency at pumping stations', Biosystems Engineering, Vol 98, pp 479-486.

Rickard, S., Morris, J., and Audsley, E. (2005), 'Possible futures for agriculture in Northern Europe during a period of policy reform', in Sylvester-Bradley, R., and Wisemann, J., eds, Yields of Farmed Species: Constraints and Opportunities in the 21st Century, University of Nottingham Press, Nottingham.

Rodríguez Díaz, J. A., Camacho Poyato, E., López Luque, R., and Pérez Urrestarazu, L. (2008), ‘Benchmarking and multivariate data analysis techniques for improving the efficiency of irrigation districts: an application in Spain', Agricultural Systems, Vol 96, pp 250-259.

Rodríguez Díaz, J. A., Pérez Ürrestarazu, L., Camacho-Poyato, E., and López Luque, R. (2005), 'IGRA. A tool for applying the benchmarking initiative to irrigated areas', Irrigation and Drainage, Vol 54, pp 307-319.

Trawick, P. (2003), The Struggle for Water in Peru: Comedy and Tragedy in the Andean Commons, Stanford University Press, Palo Alto, CA.

Vellidis, G., Tucker, M., Perry, C., Kvien, C., and Bednarz, C. (2008), 'A real-time wireless smart sensor array for scheduling irrigation', Computers and Electronics in Agriculture, Vol 61, pp 44-50.

Weatherhead, E. K. (2006), Survey of Irrigation of Outdoor Crops in 2005: England and Wales, Cranfield University, Cranfield.

Weatherhead, E. K., and Knox, J. W. (1999), 'Predicting and mapping the future demand for irrigation water in England and Wales', Agricultural Water Management, Vol 43, pp 203-218.

Zaman, A. M., Malano, H., and Davidson, B. (2009), 'An integrated water trading-allocation model applied to a water market in Australia', Agricultural Water Management, Vol 96, pp 149-159. 